\title{
Irritable bowel syndrome in primary care: The patients' and doctors' views on symptoms, etiology and management
}

\author{
Cornelis J Bijkerk MD¹, Niek J de Wit MD PhD ${ }^{1}$, Wim AB Stalman MD PhD², \\ J André Knottnerus MD PhD ${ }^{3}$, Arno W Hoes MD PhD ${ }^{1}$, Jean WM Muris MD PhD ${ }^{3}$
}

CJ Bijkerk, NJ de Wit, WAB Stalman, JA Knottnerus, AW Hoes, JWM Muris. Irritable bowel syndrome in primary care: The patients' and doctors' views on symptoms, etiology and management. Can J Gastroenterol 2003;17(6):363-368.

BACKGROUND: To facilitate the development of clinical guidelines and to direct future irritable bowel syndrome (IBS) research, insight into the perceptions of patients and general practitioners (GPs) regarding IBS is required.

OBJECTIVES: To compare patients' and GPs' views on the symptomatology, etiology and treatment of IBS.

METHODS: One hundred forty-two IBS patients and 100 GPs were requested to complete a structured questionnaire.

RESULTS: The response rates of the patients and GPs were $80 \%$ and $47 \%$, respectively. Abdominal pain and bloating were considered to be the most bothersome symptoms in IBS, by both patients and GPs. Although all patients were diagnosed by their GP as having IBS, and $62 \%$ met the Manning criteria, only $18 \%$ fulfilled the Rome II criteria for IBS. Patients consider food intolerance and GPs regard lack of fibre as the main etiologic dietary factor. Many IBS patients expect a diagnostic work-up, but GPs generally restrict this to elderly patients. GPs start IBS management with dietary advice (94\%), counselling $(77 \%)$ and drug therapy (55\%). Patients expect reassurance $(47 \%)$ and drug treatment $(37 \%)$, but dietary interventions are less appreciated (9\%).

CONCLUSIONS: Patients and GPs have different perceptions of the efficacy of diagnostic and dietary interventions in IBS. GPs should explore the patients expectations and incorporate these in their approach to IBS patients.

Key Words: Disease management; Etiology; Family practice; Functional colonic disorder; Symptomatology
Le syndrome du côlon irritable en soins primaires : Le point de vue des patients et des médecins sur les symptômes, l'étiologie et la prise en charge

HISTORIQUE : Pour faciliter l'élaboration de directives cliniques et orienter la recherche sur le syndrome du côlon irritable (SCI), un aperçu des perceptions des patients et des omnipraticiens s'impose.

OBJECTIFS : Comparer le point de vue des patients et celui des omnipraticiens sur la symptomatologie, l'étiologie et le traitement du SCI.

MÉTHODOLOGIE : Cent quarante-deux patients atteints du SCI et 100 omnipraticiens ont été invités à remplir un questionnaire structuré. RÉSULTATS : Le taux de réponse des patients et des omnipraticiens a été de $80 \%$ et de $42 \%$, respectivement. Les douleurs abdominales et les gonflements étaient considérés comme les symptômes les plus dérangeants en cas de SCI, tant pour les patients que pour les omnipraticiens. Même si tous les patients avaient été diagnostiqués par leur omnipraticien comme atteints de SCI et que $62 \%$ respectaient les critères de Manning, seulement 18 \% respectaient les critères Rome II du SCI. Les patients considèrent l'intolérance alimentaire, et les omnipraticiens, l'absence de fibres, comme le principal facteur diététique étiologique. Bien des patients s'attendaient à subir un bilan diagnostique, mais en général, les omnipraticiens le réservaient aux patients âgés. Les omnipraticiens entreprennent la prise en charge du SCI par des conseils diététiques (94\%), des conseils ( $77 \%$ ) et une pharmacothérapie (55\%). Les patients s'attendaient à être rassurés (47 \%) et à recevoir une pharmacothérapie (37\%), mais les interventions diététiques étaient moins appréciées (9\%). CONCLUSIONS : Les patients et les omnipraticiens ont des perceptions différentes de l'efficacité des interventions diagnostiques et diététiques en cas de SCI. Les omnipraticiens devraient examiner les attentes des patients et les intégrer à leur démarche auprès des patient atteints du SCI. rritable bowel syndrome (IBS) is a chronic functional gas-
trointestinal disorder characterized by recurrent episodes of
abdominal pain, altered bowel habits and/or symptoms of
bloating and abdominal distension. This symptom complex is
currently the most common gastrointestinal disorder seen in
primary care $(1,2)$. It has been suggested that patients and doc-
tors have different experiences and expectations with regards
to IBS and its treatment. If this is true, it is of major impor-
tance that both patients' and doctors' views on the symptoma-
tology, etiology, and management of IBS be explored, for better compliance with future IBS guidelines and for an optimal focus in future research.

Various diagnostic criteria for IBS have been developed in secondary care to discriminate between IBS and organic disorders. The Manning criteria (3) lists abdominal pain, altered bowel habits, mucus in stools and bloating as the major signs of IBS. These criteria have been widely used, even though validation has proven difficult (3). In 1989, a working group of gastroenterologists developed new diagnostic criteria for IBS, using a Delphi procedure (4). An important additional criteri-

\footnotetext{
${ }^{1}$ University Medical Center Utrecht, Julius Center for Health Sciences and Primary Care, Utrecht; ${ }^{2}$ Vrije Universiteit, EMGO Institute, Amsterdam; ${ }^{3}$ Maastricht University, Department of General Practice, Maastricht, The Netherlands

Correspondence: Dr NJ de Wit, University Medical Center Utrecht, Julius Center for Health Sciences and Primary Care, PO Box 85060 ,

3508 AB Utrecht, The Netherlands. Telephone 031-30-253-85-11, fax 031-30-253-90-28, e-mail n.j.dewi@@med.uu.nl

Received for publication August 1, 2002. Accepted March 14, 2003
} 
on in this recently updated 'Rome 11 definition of IBS', is abdominal pain lasting longer than three months (5). Although both the Manning and the Rome criteria may be applicable in the primary care setting, many general practitioners (GPs) are confident in diagnosing IBS using their own criteria $(6,7)$. Thompson and colleagues $(1)$, however, reported that $42 \%$ of the patients who fulfilled either the Rome or the Manning criteria for IBS were not classified as such by their GP.

Although it is often suggested that IBS symptoms are triggered by stress or dietary indiscretions (8), the actual pathophysiological course of this syndrome is as yet unknown. Research to date indicates that symptoms of IBS may be generated by a wide spectrum of factors, including abnormal mobility, increased sensitivity of the gut, inflammation, psychological factors, dietary factors and disturbed brain-gut interactions. Little is known about the perceptions patients have regarding IBS. Many relate symptom severity to stress and anxiety (9). Outpatients with IBS were found to experience more severe symptoms and were more concerned about the possible serious nature of their symptoms, including the fear of cancer, than IBS patients from primary care (10). Other reports indicated that IBS patients who consult their GP have no more psychological problems than healthy subjects $(11,12)$. The impact of IBS on a patient's lifestyle can be more precisely described using a health-related quality of life (HRQOL) measurement. This measure evaluates symptom perception, illness experience, and functional health status in relation to an illness (8). So far, however, studies evaluating the HRQOL in primary care IBS patients are scarce.

Counselling and reassurance, often accompanied by dietary advice and medication, are the first choices in the management of IBS for most GPs $(7,13-15)$. The effectiveness of therapeutic interventions for IBS is poor, and evidence based management guidelines are scarce $(1,16,17)$. Regardless of the type of management, a good patient-doctor relationship is of prime importance in the management of functional bowel disorders like IBS (18). This is supported by the observation that many IBS patients feel so insufficiently informed, particularly in regards to the background of the disease and treatment options, that some even feel stigmatized and let down by their doctor $(6,19,20)$. Such disappointment suggests that patients and doctors have different ideas about IBS management.

To date, patients' expectations regarding the management of IBS have hardly been explored and even though many treatment modalities are used, little is known about the goals that GPs set for treatment. The results of a survey evaluating both the patients' and the GPs' perceptions of symptoms, quality of life and etiology of IBS, as well as their expectations and goals for management are reported.

\section{METHODS}

An observational study amongst 142 primary care IBS patients and 100 GPs from the Utrecht and Maastricht areas in the Netherlands was performed.

\section{Patients}

Patients were randomly selected from the Utrecht General Practitioners Network (HNU), a network of 20 GPs working in six health centres affiliated with the University Medical Center of Utrecht. The HNU database contains information about the health problems and GP consultations of more than 50,000 primary care patients. Health problems have been systematically coded for almost 10 years using the International Classification of Primary Care (ICPC) (21). From this database, we identified all patients aged 18 to 65 years who were assigned the ICPC code D93 (irritable bowel syndrome) at least twice during the previous four years. Patients in this sample $(n=732)$ were then divided in three groups: 'prevalent' IBS patients (patients who had consulted for IBS at least twice in both of the previous two years); 'incident' IBS patients (new patients with a diagnosis of IBS in the previous year) and 'latent' IBS patients (patients who did not consult for IBS complaints in the previous year, but had done so more than twice in the years before). All prevalent IBS patients $(n=42)$, and a random sample of 50 incident and 50 latent cases, (total 142 IBS patients) were sent a questionnaire.

\section{Questionnaire}

The questionnaire was based on the Bowel Disease Questionnaire (BDQ), developed by Talley et al (22). The BDQ is a validated instrument for identifying IBS patients in the population at large. In addition to questions on demographic variables, abdominal and bowel symptoms, related complaints and possible causes, the authors incorporated both the Rome II (5) and the Manning (3) criteria to compare IBS as identified by these diagnostic criteria to IBS as clinically diagnosed in primary care. Questions about impairments of daily activities and work absenteeism were included and patients were asked about their views on relevant outcome parameters of IBS. Health-related quality of life was assessed using the Irritable Bowel Syndrome Quality of Life Questionnaire (IBSQOL) (23). The IBSQOL was proven valid in an earlier study whose Dutch translation has recently become available (24). To facilitate comparisons, the scores were transformed so that they ranged from zero to 100 (100 being the highest possible score, representing maximal quality of life).

A letter of invitation signed by the patient's GP accompanied the questionnaire, and nonrespondents received a written reminder.

\section{Doctors' questionnaire}

One hundred GPs were randomly selected from the Utrecht and the Maastricht University Primary Care Networks (50 from each centre) and were sent a questionnaire regarding their views on diagnostic criteria, management and treatment goals in IBS. The questionnaire was evaluated in a small pilot study. Nonresponding GPs received a reminder.

\section{Statistics}

Data analysis was performed with SPSS (Statistical Package for the Social Sciences, SPSS Inc, USA) software using descriptive statistics and cross-tabulations. Student's $t$-tests were used for subgroup analysis in the three different patient groups ('prevalent', 'incident' and 'latent' IBS patients) and the two GP groups ('Utrecht' and 'Maastricht').

\section{RESULTS}

Of the 142 randomly selected patients from the HNU, 25 $(18 \%)$ did not in retrospect meet the inclusion criteria. Reasons included uncertainty of the IBS diagnosis (11 patients), an organic disorder during follow-up (10 patients), and severe psychiatric comorbidity (four 
TABLE 1

Symptomatology as reported by irritable bowel syndrome (IBS) patients $(n=79)$

\begin{tabular}{lcc}
\hline & $\mathbf{n}$ & $\%$ \\
\hline Frequency of IBS symptoms & 31 & 44 \\
Daily or more than once a week & 13 & 18 \\
Once a week & 12 & 17 \\
Once a month & 15 & 21 \\
A few times a year & & \\
& & \\
Course of complaints during previous four weeks & 30 \\
Improvement & 22 & 53 \\
No change & 39 & 17 \\
Worsening & 13 & \\
& & \\
History of abdominal complaints & & 6 \\
< 1 year & 4 & 11 \\
1-2 years & 9 & 22 \\
2-5 years & 17 & 12 \\
5-10 years & 9 & 49 \\
$>$ 10 years & 38 & \\
& & 11 \\
IBS subtype self-assessment & & 43 \\
Pain predominant & 13 & 20 \\
Bloating predominant & 33 & 9 \\
Constipation predominant & 15 & 7 \\
Diarrhea predominant & 8 & \\
Alternating defecation predominant & & \\
\hline
\end{tabular}

patients). In addition, 18 patients (13\%) were excluded because of admission to hospital or nursing home (seven patients) or the inability to fill out the questionnaire (11 patients). The remaining 99 patients were sent a questionnaire, which was returned by 79 patients ( $80 \%$ response rate). The mean age of the respondents was 44.5 years $(S D=17.4)$. There were no significant differences in age or sex between the 'prevalent', 'incident' and 'latent' IBS patients.

The response rate to the GP questionnaire was 47\% $(47 / 100)$. There were no significant differences in response rate, age or sex between the GP groups from the two university networks.

\section{Symptomatology in IBS}

More than half of the responding patients reported having symptoms on a weekly or even daily basis during the previous year (Table 1). Seventy per cent reported having intermittent symptoms. Patients reported a median abdominal pain score of $2.00(\mathrm{SD}=1.85)$ on a scale of one to four in the active phase of their IBS. Symptom severity was reported as moderate to severe by the majority $(63 \%)$ of the respondents, mild by $19 \%$, and very severe by $10 \%$. Almost half of the patients reported a history of abdominal complaints lasting more than 10 years, while only $6 \%$ noted that the symptoms had occurred within the last year. Bloating-predominant IBS was the most frequently reported subtype of IBS (43\%) (Table 1). There were no statistically significant differences between the 'prevalent', 'incident', and 'latent' patients with regards to the above items. Patients reported bloating (27\%) and abdominal pain (27\%) as their most bothersome symptoms, while complaints such as diarrhea (10\%), constipation (14\%), and related symptoms (straining $(9 \%)$, urgency $(1 \%)$, and feelings of incomplete
TABLE 2

Classification of irritable bowel syndrome (IBS) patients $(n=79)$ according to Rome and Manning criteria as reported by the patients.

\begin{tabular}{lcc}
\hline Definition of IBS* & $\mathbf{n}$ & $\%$ \\
\hline Rome II $\geq 2$ & 14 & 18 \\
Manning $\geq 2$ & 48 & 62 \\
Manning $\geq 3$ & 37 & 47
\end{tabular}

* Rome II criteria (5): Abdominal discomfort or pain for at least 12 or more consecutive weeks in the preceding 12 months, with at least two of the three following features: 1) Relief with defecation; and/or 2) Onset associated with a change in looser stool frequency; and/or 3) Onset associated with a change in stool consistency. Manning criteria (3): Abdominal pain with 2/3 or more of the following features: 1) Abdominal pain relieved by defecation; and/or 2) Abdominal pain associated with more frequent stools; and/or 3) Abdominal pain associated with looser stools; and/or 4) Abdominal distension or bloating; and/or 5) Feeling of incomplete defecation; and/or 6) Mucus in stools

evacuation $(6 \%)$ were considered minor problems. Only one patient reported mucus as the most bothersome symptom. These observations were in line with the doctors' views on symptomatology: almost all GPs considered abdominal pain and bloating as the most characteristic IBS symptoms (95\% and $86 \%$, respectively).

\section{Comorbidity}

Heartburn was reported by $32 \%$ of the IBS patients and dyspeptic symptoms by $79 \%$. Belching, borborygmi and flatulence were also frequently reported $(42 \%, 64 \%$, and $67 \%$, respectively). Furthermore, concomitant pain syndromes were prevalent: $61 \%$ reported headache, $65 \%$ lower backache and $66 \%$ arthralgia or muscle pains. Fatigue and anorexia were reported by $47 \%$ and $26 \%$ of the patients, respectively. Urinary tract symptoms were rare $(16 \%)$. Half of the patients reported psychological problems like sleeplessness $(36 \%)$, nervousness (51\%), and depressed feelings (59\%); $25 \%$ reported a major depression during the previous year and $22 \%$ an anxiety disorder. Again, there were no significant differences between the different patient groups with regards to these items.

\section{Diagnostic criteria for IBS}

Although all patients had a clinical diagnosis of IBS ascribed to them by their GP, only a minority ( $18 \%)$ completely fulfilled the Rome II diagnostic criteria for IBS (Table 2). In contrast, $62 \%$ of the patients reported two key symptoms fitting in the Manning criteria for IBS, while almost half reported having three or more symptoms belonging to the Manning criteria (Table 2).

The diagnostic criteria that general practitioners used for a clinical diagnosis of IBS included bloating or a feeling of abdominal distension (87\%) and the absence of alarming features $(87 \%)$. Although only two GPs (4\%) knew either the Manning or Rome criteria for IBS, $63 \%$ considered recurrent abdominal pain lasting more than three months - the core symptom in the Rome II definition - to be the crucial symptom for diagnosing IBS. Other criteria used in the Rome II definition (eg, relief after defecation, altered frequency of stool and changed consistency of stool) were less frequently reported (33\%, 22\%, and 35\% respectively).

Forty-nine per cent of GPs reported that their primary focus in performing diagnostic tests in patients suspected of IBS was to exclude an organic disorder. Their diagnostic strategy depended on the patient's age. Patients under 50 years were rarely referred for diagnostic investigations. Half (48\%) of the 
TABLE 3

Quality of life (QOL) and productivity in primary care irritable bowel syndrome (IBS) patients. QOL scored on the Irritable Bowel Syndrome Quality of Life Questionnaire (IBSQOL) using nine subscales $(0=$ minimum, $100=$ optimal)

\begin{tabular}{lccc}
\hline & N & mean & SD \\
\hline IBS QOL subscales & 66 & 65.6 & 20.6 \\
$\quad$ Emotional & 67 & 75.3 & 34.8 \\
Mental health & 75 & 79.4 & 19.3 \\
Sleep & 74 & 74.3 & 19.0 \\
Energy & 69 & 58.1 & 35.9 \\
Physical functioning & 75 & 71.7 & 39.0 \\
Food & 73 & 79.6 & 38.0 \\
Social role & 72 & 63.4 & 21.0 \\
Physical role & 71 & 29.3 & 21.3 \\
Sexual relations & & & \\
& & & \\
Productivity & 66 & 77 & 27 \\
Productivity during previous four weeks & 32 & 15 & $(1-104)$ \\
Absenteeism days (median, range) & 24 & 21 & $(1-181)$ \\
Less-productive days (median, range) & 24 & & \\
\hline
\end{tabular}

GPs indicated that they only considered laboratory testing (etythrocyte sedimentation rate, full blood count, fecal blood test or antigliadine) for patients over 50 years of age. Only 9\% of the GPs considered a once-in-a-lifetime endoscopy useful in IBS.

\section{Etiology of IBS}

Patients frequently attributed a somatic cause (39\%), food intolerance $(37 \%)$, stress $(43 \%)$ or a family factor $(11 \%)$ to their IBS symptoms. There were no differences between the three IBS patients groups with regards to these perceptions. Twenty-one per cent of the patients reported having food intolerance for one or more food products, with intolerance for soda, fat and spicy foods being the most frequently reported (42\%, 58\%, and 60\%, respectively). Provocation of IBS symptoms by dairy products (eg, cheese and milk) was less frequently reported ( $9 \%$ and $16 \%$, respectively). Seventy-five per cent reported having excluded food products from their diet, most of them with success. Sixteen per cent reported intolerance for dietary fibre, while one-fifth of the IBS patients reported benefiting from a high fibre diet.

Most GPs considered stress, fibre deficiency and disturbed motility to be the most important etiological factors $(71 \%$, $83 \%$, and $62 \%$, respectively), with gut hypersensitivity (26\%), food intolerance $(4 \%)$ or brain-gut disturbance $(4 \%)$ as less frequently reported mechanisms.

IBS was found to severely affect sexual functioning but to cause only a mild to moderate impairment of physical and emotional IBSQOL dimensions (Table 3). Patients reported a mean productivity score of 77 on a $100 \mathrm{~mm}$ Visual Analogue Scale over the past four weeks (SD 26). More than one third of the respondents reported IBS-related absenteeism from work - on average 15 days in the past year (Table 3 ).

\section{Management of IBS}

With regards to IBS management, patients expected reassurance and counselling from their doctor (mentioned by $47 \%$ and $30 \%$ of the patients, respectively), as well as pharma- cotherapy $(37 \%)$, a proper diagnostic work-up $(38 \%)$ or specialist referral (39\%). Dietary interventions were less appreciated $(9 \%)$. Most patients stated that improvement of the most bothersome symptom should be the prime target for treatment ( $46 \%$ wanted to focus on bloating, $35 \%$ on pain). Only $8 \%$ considered global symptom improvement, and $11 \%$ chose quality of life improvement as the most important goal in treatment.

When asked for their experiences with IBS treatment, one third of the patients reported adequate relief of IBS symptoms after reassurance and counselling by their GP (34\%). A minority of the patients $(13 \%)$ had been treated with antispasmodic drugs, half of them with success. One-third of the patients reported benefit from fibre supplements. Though $61 \%$ had been referred to a dietician, only $8 \%$ reported benefiting from dietary advice.

Most general practitioners considered dietary advice (93\%), counselling (77\%) and pharmacotherapy (55\%) to be of paramount importance in the treatment of IBS. Sixty-three per cent gave routine lifestyle advice and only $4 \%$ gave behavioural therapy. Drug treatment for IBS management was usually started with fibre supplements $(67 \%)$ or antispasmodics (25\%).

Global symptom improvement was the target for pharmacotherapy in IBS for most (70\%) GPs. A minority evaluated treatment response on improvement of the predominant symptom $(28 \%)$ or quality of life (2\%). Only $10 \%$ of the GPs continued fibre supplements or antispasmodics as maintenance therapy after initial success.

\section{DISCUSSION}

The results of our survey demonstrate that patients' and physicians' perceptions of IBS in primary care overlap, and that, with the exception of diagnostic and dietary interventions, GPs management meets the patients' expectations. Bloating and abdominal pain are both the most bothersome symptoms for patients as well as the predominant diagnostic criteria for GPs. The GPs in this study used diagnostic criteria that coincided with the Manning criteria, but correlated poorly with the Rome 11 criteria. The latter may be less applicable in primary care. Both GPs and patients consider counselling, reassurance and pharmacotherapy to be the key steps in IBS management. Dietary advice, though commonly given by GPs, is poorly appreciated by patients.

The high comorbidity we found among IBS patients, especially of dyspepsia, confirms earlier reports - some researchers consider the two conditions to be directly related $(25,26)$. Earlier studies have also reported an over-representation of psychological problems among IBS patients (27). In this primary care IBS population we found depression or anxiety in one-fifth of the patients. In contrast, psychiatric disorders are reported in up to $50 \%$ of the IBS patients in secondary care (28).

Earlier reports on the applicability of the Rome and the Manning diagnostic criteria in primary care showed conflicting results $(1,7,29)$. Our study demonstrates that, although most GPs are not familiar with the terminology of the Manning criteria, the majority is implicitly using these criteria for diagnosing IBS patients. The fact that only one-third of the IBS patients in our survey fulfilled the Rome 11 definition of IBS may indicate that this set of diagnostic criteria is not optimal for use in primary care. This may be explained by differences in 
disease spectrum (primary care IBS patients having milder symptoms), consultation behaviour or in symptom interpretation (in our survey bloating was as predominant as pain). As most GPs underlined the key feature of the Rome definition (pain for at least three months), the low compliance with the Rome criteria may simply be the result of GPs valuing other symptoms more (bloating) or less important (change in stool and relief with defecation). From a primary care point of view, abdominal distention may need a more prominent place in the diagnostic criteria for IBS. Subclassification of IBS guided by defecation type, as suggested by the Rome committee (5), may be less applicable in primary care because altered defecation, constipation or diarrhea were infrequently reported in our patient sample.

For GPs IBS is a positive instead of an exclusion diagnosis. They restrict the use of diagnostic tests to elderly patients in order to exclude a malignant process. This may often be disappointing for patients, as our results indicate that many IBS patients expect a diagnostic work-up either in primary care or after referral.

The etiology of IBS varies widely in the views of both patients and doctors. Many patients attribute their symptoms to either a somatic cause, stress or food intolerance, while GPs perceive IBS etiology to be related to stress, fibre deficiency and disturbed motility. So far, evidence for an unique etiological role for any of these factors is scarce, but attributions like fear of cancer and stress do explain differences in consultation for IBS $(1,10,11)$.

Both patients and doctors see an important role for diet in the etiology of IBS, but they relate it to different dietary factors. In contrast to GPs, many patients relate IBS to food intolerance; $75 \%$ of the patients had empirically excluded food substances to control IBS symptoms, most of them successfully. The benefit of exclusion diets in IBS remains controversial. Although the prevalence of food intolerance is often reported as high as $45 \%$, it can only be objectively confirmed in $2 \%$ to $8 \%$ of the IBS population $(30,31)$.

\section{REFERENCES}

1. Thompson WG, Heaton KW, Smyth GT, Smyth C. Irritable bowel syndrome in general practice: Prevalence, characteristics, and referral. Gut 2000;46:78-82.

2. Jones R, Lydeard S. Irritable bowel syndrome in the general population. BMJ 1992;304:87-90.

3. Manning AP, Thompson WG, Heaton KW, et al. Toward positive diagnosis of the irritable bowel. Br Med J 1978;2:654

4. Thompson WG, Dotevall G, Drossman DA, et al. Irritable bowel syndrome: Guidelines for the diagnosis. Gastroenterol Int 1989;2:92-5

5. Thompson WG, Longstreth GF, Drossman DA, Heaton KW, Irvine EJ, Muller-Lissner SA. Functional bowel disorders and functional abdominal pain. Gut 1999;45(Suppl II):II43-II47.

6. Dixon-Woods M, Critchley S. Medical and lay views of irritable bowel syndrome. Fam Pract 2000;17:108-13.

7. Thompson WG, Heaton KW, Smyth CG, Smyth C. Irritable bowel syndrome: The view from general practice. Eur J Gastroenterol Hepatol 1997;9:689-92.

8. Drossman DA, Creed FH, Olden KW, Svedlund J, Toner BB, Whitehead WE. Psychological aspects of the functional gastrointestinal disorders. Gut 1999;45(Suppl II):II25-II30.

9. Drossman DA. Do psychological factors define symptom severity and patient status in irritable bowel syndrome? Am J Med 1999; 107:41S-50S.

10. Van der Horst HE, van Dulmen AM, Schellevis FG, van Eijk JT, Fennis JF, Bleijenberg G. Do patients with irritable bowel syndrome in primary care really differ from outpatients with irritable bowel syndrome? Gut 1997;41:669-74.
GPs see fibre deficiency as the main dietary factor, and regard dietary advice, either in practice or by a dietician, as one of the primary steps in IBS management. This is not appreciated by patients, probably because they have ruled out dietary factors after having excluded intolerance for food substances themselves.

Although the evidence for efficacy for most drug interventions in IBS is poor, it remains a cornerstone of management in IBS (32-34). More than half of the GPs in our study started IBS management with pharmacotherapy. This is in line with drug prescription rates in IBS in the literature, often reported as high as $80 \%(7)$.

On average, IBS only mildly affects quality of life and productivity in primary care patients. Mean scores on the IBSQOL in our survey were comparable to those of referred IBS patients (mean score 56 to 92) and lower than those of patients without IBS (mean score 90 to 100) (24). We could not confirm the observation that chronic IBS patients are more likely to experience the social consequences of their illness (35).

\section{CONCLUSION}

In conclusion, patients and doctors in primary care generally have similar perceptions of IBS symptoms and etiology. However, patients tend to overestimate the role of food intolerance in the etiology of IBS, and the need for diagnostic tests in diagnosing the syndrome. Given its low appreciation, the effectiveness of present dietary advice by GPs may be questioned.

As for IBS therapy, GPs aim at global symptom improvement, while patients consider improvement of their most bothersome symptom as the main target. Both agree on the importance of counselling, reassurance and pharmacotherapy, although from either therapeutic interventions in IBS less than $50 \%$ of the patients in our study group reported benefit.

11. Kettel J, Jones R, Lydeard S. Reasons for consultation in irritable bowel syndrome: Symptoms and patients characteristics. Br J Gen Pract 1992;42:459-61.

12. Talley NJ, Boyce PM, Jones M. Predictors of health care seeking for irritable bowel syndrome: A population based study. Gut 1997;41:394-8.

13. Paterson WG, Thompson WG, Vanner SJ, et al. Recommendations for the management of irritable bowel syndrome in general practice. CMAJ 1999;161:160.

14. De Waal M, Donker G, van der Velden J. Digestive disease in the general population and in primary care (in Dutch). Utrecht. NIVEL/Dutch Digestive Disease Foundation, 1992.

15. Jansen HA, Borghouts JA, Muris JW, Metsemakers JF, Koes BW, Knottnerus JA. Health status and management of chronic non specific abdominal complaints in general practice. Br J Gen Pract 2000;50:375-9

16. Camilleri M. Management of irritable bowel syndrome. Gastroenterology 2000;120:652-68.

17. Jones J, Boorman J, Cann P, et al. British Society of Gastroenterology guidelines for the management of irritable bowel syndrome. Gut 2000; 47( suppl II):1-19.

18. Jones R. IBS: Prime problem in primary care. Gut 2000;304:7.

19. Van Dulmen AM, Fennis JFM, Mokkink HG, Van der Velden HG, Bleijenberg G. Doctors' perception of patients' cognitions and complaints in irritable bowel syndrome at an out-patient clinic. J Psychosom Res 1994;38:581-90.

20. O'Sullivan MA, Mahmud N, Kelleher DP, Lovett E, O'Morain CA. Patients knowledge and educational needs in irritable bowel 
syndrome. Eur J Gastroenterol Hepatol 2000;12:39-43.

21. Classification Committee of WONA. ICHPPC-2 defined. International Classification of Health Problems in Primary Care. Oxford: Oxford University Press, 1983.

22. Talley NJ, Phillips SF, Melton J, Wiltgen C, Zinmeister AR. A patient questionnaire to identify bowel disease. Ann Intern Med 1989;111:671-4.

23. Hahn BA, Kirchdoerfer LJ, Fullerton S, Mayer E. Evaluation of a new quality of life questionnaire for patients with irritable bowel syndrome. Aliment Pharmacol Ther 1997;11:547-52.

24. Hahn BA, Kirchdoerfer LJ, Fullerton S, et al. Patient-perceived severity of irritable bowel syndrome in relation to symptoms, health resource utilization and quality of life. Aliment Pharmacol Ther 1997;11:553-9.

25. Agreus L, Svaerdsudd K, Nyrén O, Tibblin G. Irritable bowel syndrome and dyspepsia in the general population: Overlap and lack of stability over time. Gastroenterology 1995;109:671-80.

26. Den Hartog G, Mulder CJJ, Thies JE, Wiersma TJG. The constipated stomach. An underdiagnosed problem in patients with abdominal pain? Scand J Gastroenterol 1998;33:41-6

27. Donker GA, Foets M, Speeuwenberg P. Patients with irritable bowel syndrome: Health status and use of health care. Br J Gen Pract 1999;49:787-92.

28. Drossman DA, Whitehead WE, Camilleri M. Irritable bowel syndrome: A technical review for practice guideline development. Gastroenterology 1997;112:2120-37.

29. Agreus L. Rome? Manning? Who Cares? Am J Gastroenterol 2000;95:2679-80

30. Stockbrugger RW, Pace F, eds. The Irritable Bowel Syndrome Manual. London: Mosby-Wolfe, 1999.

31. Niec AM, Frankum B, Tally NJ. Are adverse food reactions linked to irritable bowel syndrom? Am J Gastroenterology 1998;93:2184-90.

32. Klein KB. Controlled treatment trials in the irritable bowel syndrome: A critique. Gastroenterol 1988;95:232-41.

33. Jailwala J, Imperiale TF, Kroenke K. Pharmocologic treatment of the irritable bowel syndrome: A systematic review of randomized, controlled trials. Ann Intern Med 2000;133:136-47.

34. Akehurst R, Kaltenhalter E. Treatment of irritable bowel syndrome; review of randomised controlled trials. Gut 2001;48:272-82.

35. Guthrie EA, Creed FH, Whorwell PJ, Tomenson B. Outpatients with irritable bowel syndrome: A comparison of first time and chronic attenders. Gut 1992;33:361-3. 


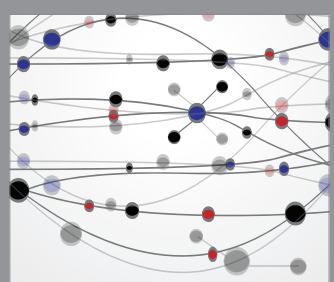

The Scientific World Journal
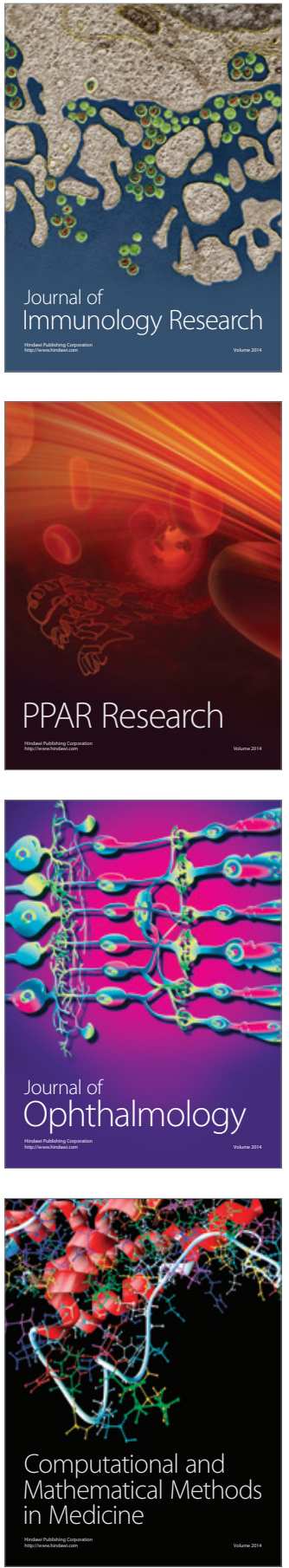

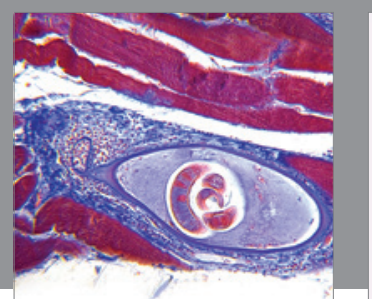

Gastroenterology Research and Practice

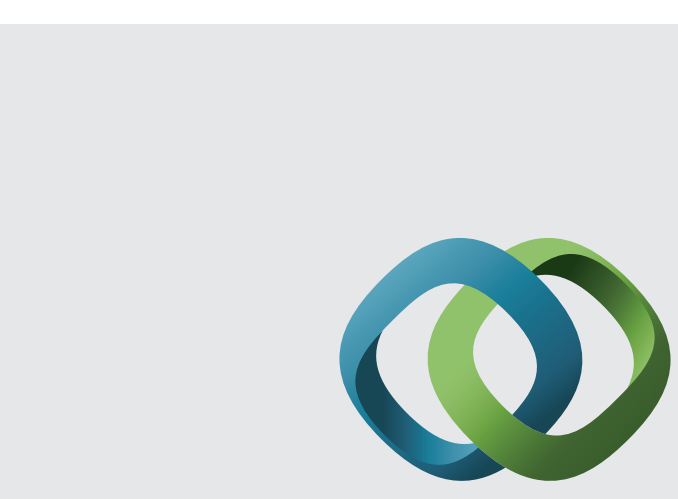

\section{Hindawi}

Submit your manuscripts at

http://www.hindawi.com
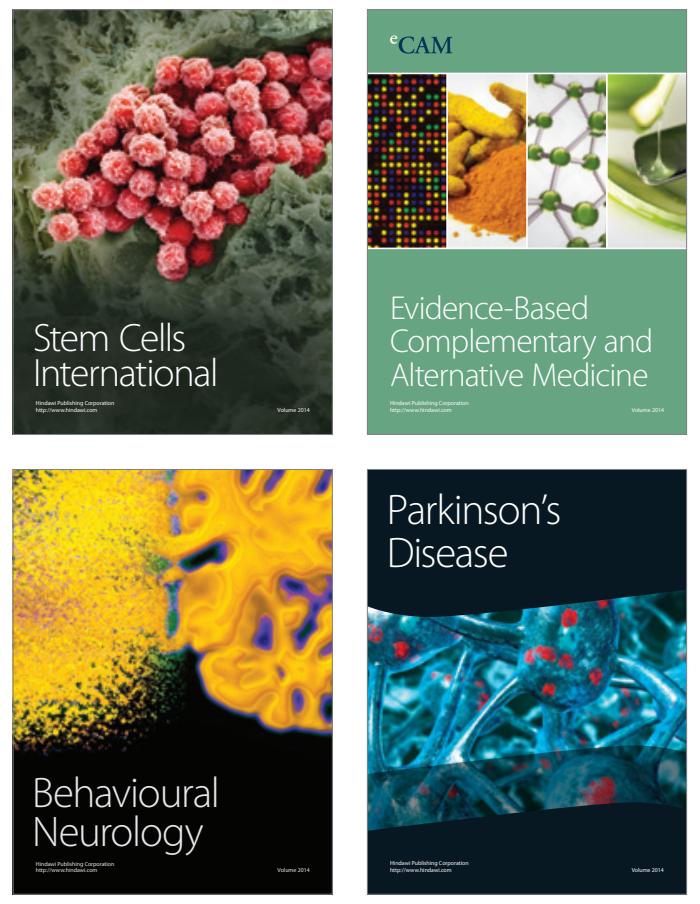
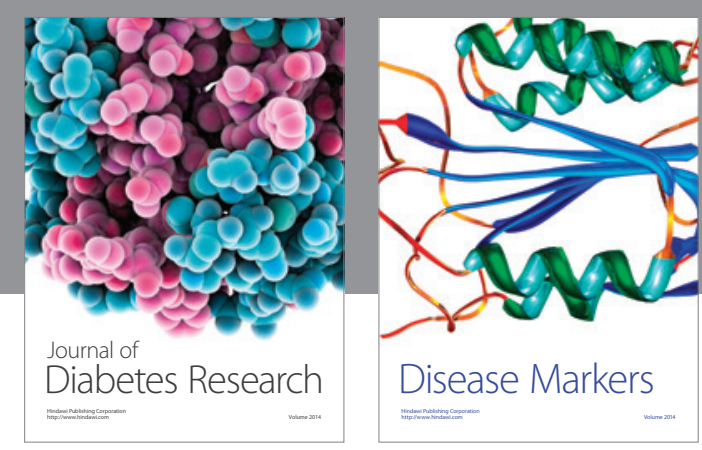

Disease Markers
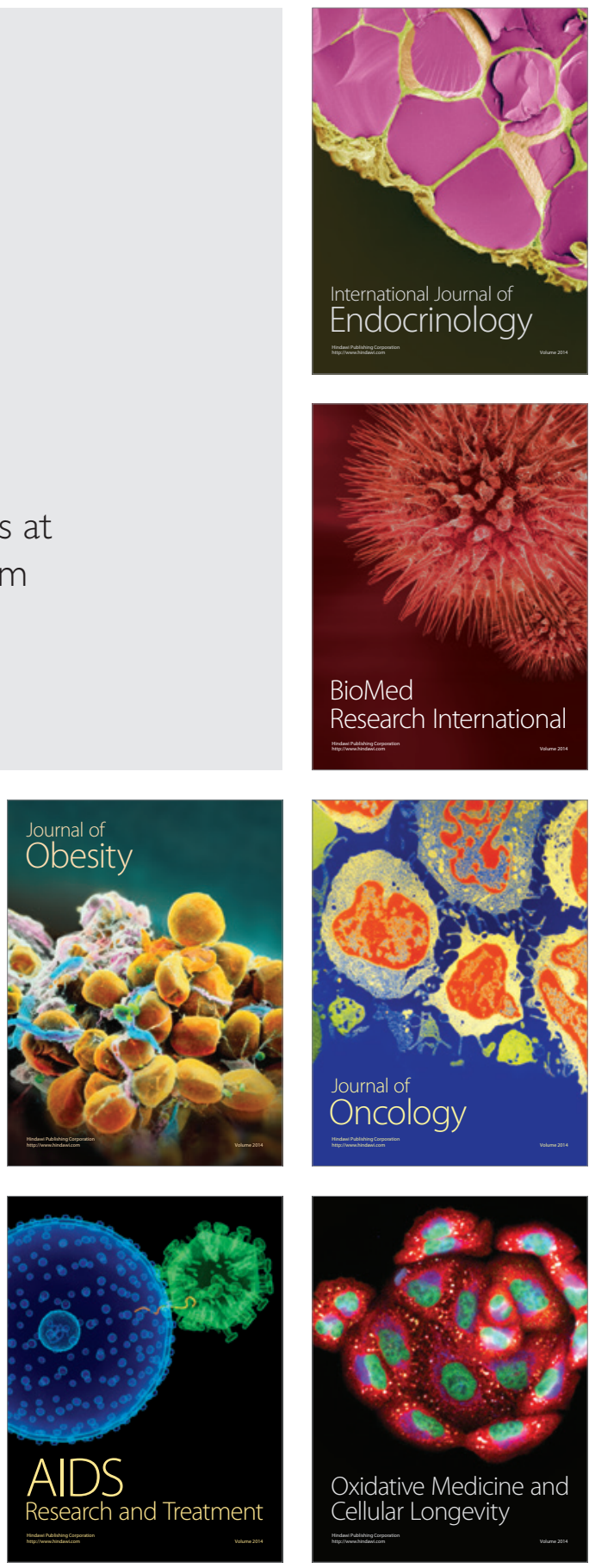